\title{
Conversion of Pine Sawdust into Polyhydroxyalkanoate Bioplastics
}

Ganesh Mohan+, Robert Lee Johnson ${ }^{\dagger}$ and Jian Yu ${ }^{\dagger}$

†Hawai' $\mathrm{i}$ Natural Energy Institute, University of Hawai`i at Manoa, 1680 East West Road, POST 109, Honolulu, HI 96822, USA

Email: jianyu@hawaii.edu

Supporting information contains 3 pages with 3 figures 
Figure S1. Utilization of Furfural and HMF by $C$. necator
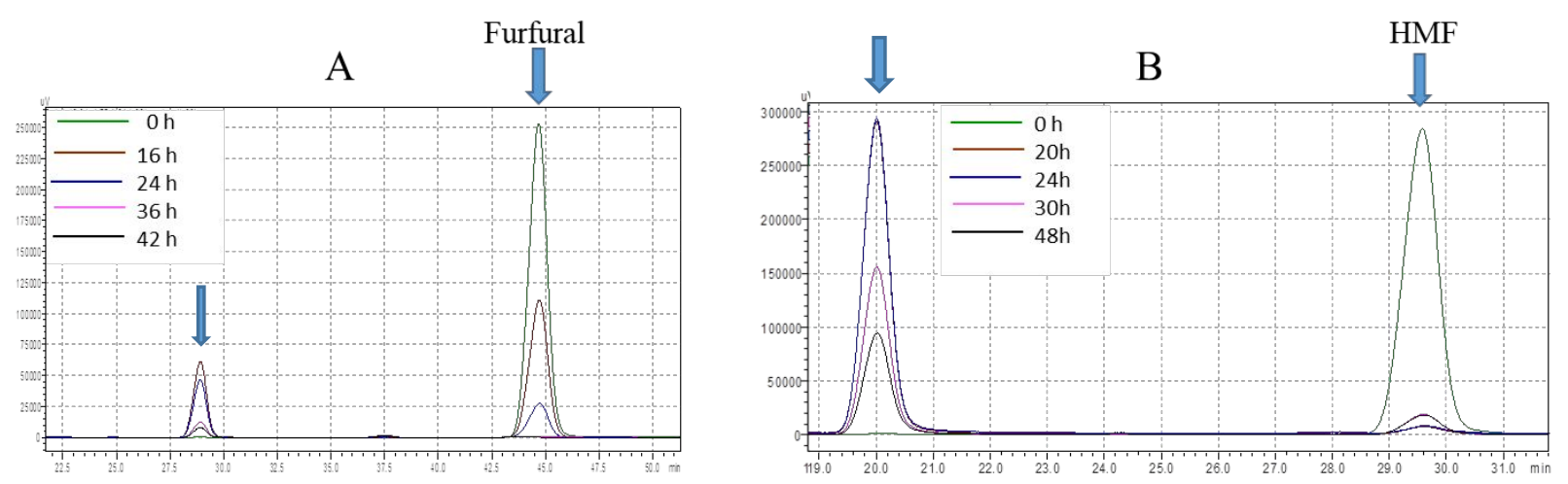

A) Chromatogram of furfural $(2.5 \mathrm{mM})$ reduction with an intermediate (retention time $28 \mathrm{~min})$ in LA $8 \mathrm{~g} / \mathrm{L}$ (C/N 30) fermentation

B) Chromatogram of HMF $(2.5 \mathrm{mM})$ reduction with an intermediate (retention time $20 \mathrm{~min})$ in LA $8 \mathrm{~g} / \mathrm{L}$ (C/N 30) fermentation

Figure S2. Utilization of phenolic model compounds on the growth of $C$. necator

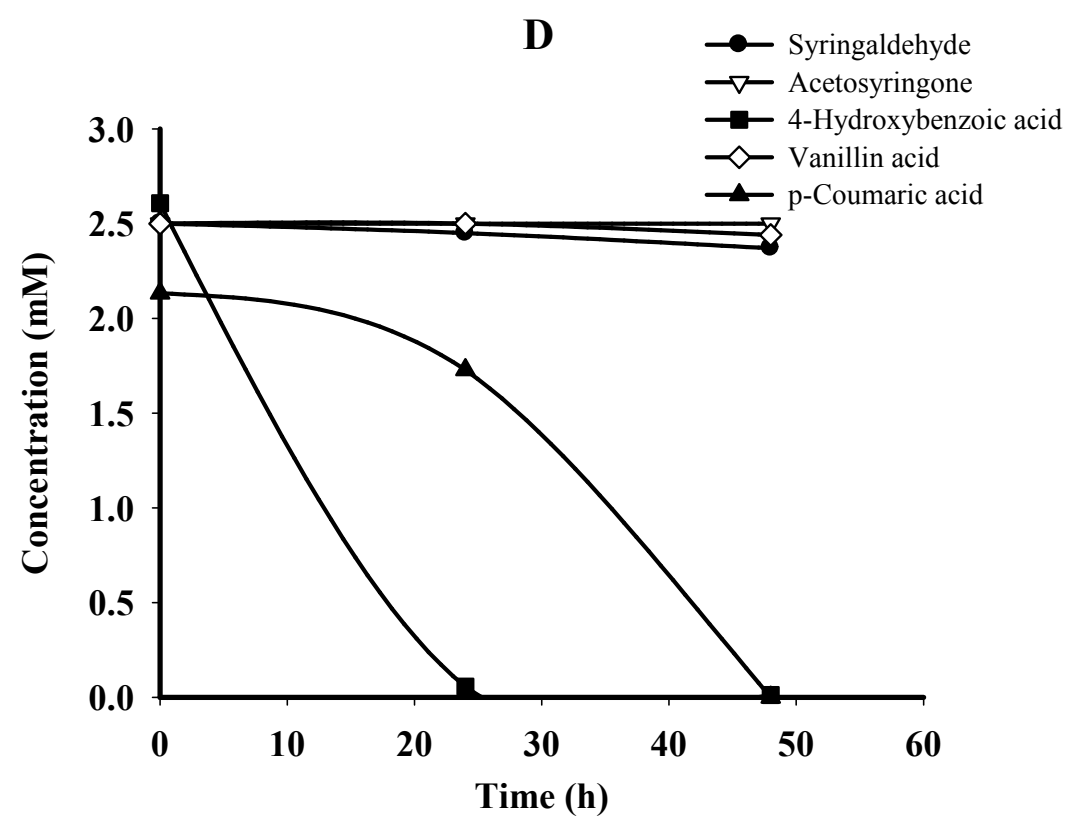


Figure S3. Effect of humic acid on growth of $C$. necator

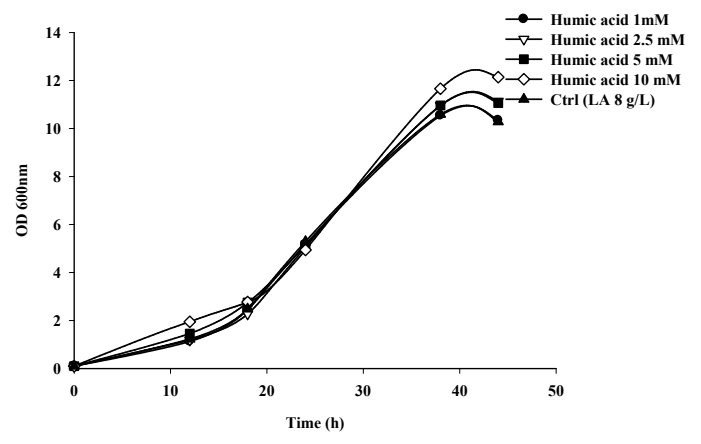

